\title{
Barriers of the Visually Impaired Persons in the electoral process in Zambia
}

\author{
Pauline Mileji ${ }^{1 *}$, Beatrice Matafwali ${ }^{2} \&$ Gistered Muleya $^{3}$ \\ ${ }^{1}$ Kwame Nkrumah University, Zambia \\ ${ }^{2,3}$ University of Zambia \\ *Corresponding Author \\ DOI: https://dx.doi.org/10.51244/IJRSI.2021.8311
}

\begin{abstract}
The study sought to identify barriers faced by persons with Visual Impairment in the electoral process in Zambia. A phenomenological research study design was used. Data was collected using interviews and Focus Group Discussions (FGDs). Purposive sampling procedure was used to sample thirty participants.The key findings were that the Visually Impaired persons face many barriers of which the following were part of; lack of education, lack of social network, lack of confidentiality, ignorance, fear, stigma, inaccessible information, transport and suitable facilities. The study recommends that adequate civic education should be delivered to the Visually Impaired persons.In this regard, there is need to adopt the human rights model that will allow the Visually Impaired persons to participate at all levels of the electoral process.
\end{abstract}

Keywords; Inclusion, Human Rights, Electoral Process

\section{INTRODUCTION}

$\mathbf{S}$ tudies have indicated that the participation of the Visually Impaired (VI) in the electoral process is not without barriers. The Resource Book on Disability Inclusion (2017) refers to barriers as the process, mindset or structures that prevent men, women and children with disabilities from equal access to information, facilities and basic services that are available to the general populace. In this sense, societal attitude to disability, or the way persons with disabilities are perceived and treated, may serve either as an enabling or disabling factor to inclusion.

A report by the European Union Agency for Fundamental Rights (2014) revealed that European Union (EU) member states have made significant progress in integrating the rights to political participation of persons with disabilities into their national legal and policy framework. However, it was established that legal and administrative barriers continue to prevent some persons with disabilities from participating in political life on equal basis with others. The following barriers were identified;

a. Legal restrictions on the right to vote of some persons with disabilities particularly those with psychosocial or intellectual impairments;

b. Inaccessible and cumbersome administrative process which can prevent persons with disabilities from voting in practice; and c. Difficulties in accessing complaints mechanisms in cases where persons with disabilities face problems in exercising the right to vote.

It is clear from the findings of the EU that participation of the VI implies that the person with a disability can fully take part in everyday, ordinary aspects of life, with an emphasis on building lasting connections with his/her community. However, the principle does not only highlight the physical presence of persons with disabilities in societal actions and events, but stresses the importance of political engagement of persons with disabilities in decisions that relate to them. Furthermore, it is clear from this EU study that even though there are many legal frameworks that exist for the inclusion of persons with disabilities in the electoral processes, gaps in the law remain.

Munemo (2015); ILO (2001) \& Mileji (2016) have indicated that participation of people with Visual Impairment in the governance and electoral structures of their communities is a right and, therefore a developmental issue. In Zambia, the right to participation in national affairs is of great importance as it is enshrined in article 75(2) of the Constitution of Zambia. However, according to Zambia Association of Persons with Disabilities (2017) people with disabilities face numerous barriers to participate in the electoral process.

The following were the objectives of this study;

1. To establish the electoral needs of people with visual impairment in Zambia

2. To find out the level of participation of the Visually Impairment in the electoral process

3. To establish the barriers that have contributed to the non-participation of the people with visual impairment in the electoral process

4. To determine how the electoral process can be made more inclusive for individuals with visual impairment

Studies from several countries like Ghana by Sackey (2014) and Vietnam by Human Rights Watch (2012) have consistently linked lack of financial resources, negative attitudes, low educational attainment and inaccessible physical environment to the low political participation of persons with disabilities. Beside these factors, disability makes it difficult for some persons to interact with other members of society, thus limiting interaction with their peers and the opportunities 
to understand the political process (Meekosha, 1999; Schur et al. 2013). In some instances, electoral laws have also disenfranchised some persons with intellectual and psychosocial disabilities from participating in politics because they are deemed incapable of making sound political decisions (Human Rights Watch, 2012; International Foundation for Electoral System, 2014; Sackey, 2014).

A strategy towards creating a better understanding of the rights of persons with disabilities and eradicating attitudinal, physical, and institutional barriers will go a long way towards increasing the participation of persons with disabilities in politics. In reference to historical exclusion, the United Nations (UN) General Assembly adopted the Convention on Rights of Persons with Disabilities (CRPD) in December 2006. The CRDP report is an international human rights treaty, which promotes, protects, and ensures the full enjoyment of human rights by persons with disabilities. The CRPD is the guiding international standard in disability inclusion. Article 29 of the treaty focuses on participation in political and public life. It calls on states to ensure that persons with disabilities can effectively and fully participate in political and public life. It also calls on states to ensure that all persons with disabilities can effectively and fully participate in political and public life on equal basis with others, directly or through freely chosen representatives, including the right and opportunity for persons with disabilities to vote and be elected (CRPD Protocol, 2012). Whether this is the case in Zambia, this study will have to establish.

Buckmaster and Thomas (2009) indicated that exclusion referred to a lack of opportunities to participate in social, economic and/or political life. Article 19 of the UN Convention on the Rights of People with Disabilities (2006) underpinned the importance of life in and as part of the community for people with disabilities. Across the world, people with visual impairment have been subjected to discrimination and alienation from ordinary life and relationships. They have also been excluded and exposed to powerlessness within service systems coupled with loneliness and isolation (The National Council on Disability, 2012). This situation appears to be the case in Zambia. However, this study has to establish.

Sherwin (2010) also argued that social inclusion continued to be inspirational for many people with visual impairment. The following quotation from the Report of the National People with Disabilities and Career Council of Australia (2009) perhaps best summarized the plight of people with disabilities.

\footnotetext{
'We desire a place within the community. This place is not just somewhere to lay down our heads, but a place which brings comfort and support with daily living, friendship, meaningful work, exciting recreation, spiritual renewal, and relationships in which we can be ourselves. And out of this, great things may flourish.'
}

The above quotation effectively captures the extent to which people with disabilities have been excluded, not only in the political arena which forms the thrust of this study, but in other spheres of social inclusion namely active participation in community living. People with visual impairment have limited hope or no hope at all of going to school, getting a job, having their own home, creating a family and raising their children enjoying a social life or voting. For the vast majority of the world's people with disabilities, shops, public facilities and transport, and even information are largely out of reach (ILO, 2001). Therefore, this study establishes the barriers of the Visually Impaired Persons in the electoral process in Zambia.

\section{METHODOLOGY AND DESIGN}

This study took a qualitative approach and employed a phenomenological research design. The study drew 30 participants among them were officials from Zambia Agency for Persons with Disabilities(ZAPD), Electoral Commission of Zambia(ECZ), Forum for Democratic Process (FODEP) and the Visually Impaired persons in Lusaka and Kabwe. Purposive sampling techniques were employed to identify the participants. Interview guideand focus group discussions (FGDs) were used to gather data. Data from interviews and FGDs was transcribed having read text files and listened to the tape recorders thoroughly for a general understanding. Common themes were then identified and clustered to get relevant information for this study.

\section{PRESENTATIONOF FINDINGS}

\section{A. Participation of the VI in the electoral process.}

The study has established that the Electoral Commission of Zambia(ECZ) and Zambia Association of Persons with Disabilities(ZAPD) are at the centre of managing the affairs of the disabled persons. The roles of the two managing institutions are that, the ECZ ensures that the disabled persons are included in the electoral process according to the Electoral Act. Meanwhile, Zambia Federation for Persons with Disabilities (ZFPD) and ZAPD is the medium of communication between the disabled persons and the government while human rights uphold people's rights.

Furthermore, it was established that the approaches employed by ECZ were the provision of braille paper jacket, involving organizations like ZAPD and Zambia Federation of People with Disability (ZFPD) to transcribe braille materials and communicate to the visually impairedpersons as voter educators about the electoral process and its importance.

When the participants were asked to state the level of participation by the visually impaired (VI) in the electoral process. One participant who was interviewed had this to say;

The electoral process in Zambia has not made it possible for the people with visual impairment to participate in the electoral process. The political landscape is hostile for them. This is despite 
institutions like Zambia Federation of People with Disabilities (ZFPD) and the Zambia Association of Persons with Disabilities (ZAPD).Hence, the visually impaired cannot participate in the electoral process with inadequate information

In this regard,there is need to adopt alternative participation mechanisms that will allow the vivsually impaired persons to exercise the right to public participation. One participant said;

Though the electoral process has some activities which are seemingly supporting the participation of the visually impaired in the electoral process; the ground has still had not really been leveled. Hence, the visually impaired need sufficient information flow for them to participate in the electoral process.

Another participant from the interviews said;

we have tried all we can to communicate but the visually impaired persons are not so many in numbers. Besides, it seems as if they are not interested to participate in national matters. There is need for the visually impaired persons themselves to take the lead and be vibrant in all public affairs if their participation is to be enhanced and recognized.

\section{B. Barriers for their inclusion}

In order to respond to a research question which sought to establish the barriers to the inclusion of people with visual impairment in the electoral process, and the question was;

What are the barriers to the inclusion of people with visual impairment in the electoral process?

The following themes emerged; Lack of voter Education, Electoral equipment and Distance to polling station and violence

Distance to polling station and violence

One VI person interviewed said;

most polling stations are placed in far areas making it impossible for me who has no sight to go especially when I have no aid, making me stay away from participating in elections and so my voice is not heard because my choice is not marked as a result we are ruled by other people's choices. My and I, fellow blind man, have not voted before. Really we are treated as if we are a dead group of people or better still not existing, It's very painful

Another VI interviewed said the following;

Electoral violence has been a serious issue in our country. We fail to walk in town worse off attend political rallies for fear of being beaten to death by the angry political opponents. I had the privilege of being in Kaoma during a campaign of a named Member of parliament and suddenly there was confusion and I could smell smoke which made me hit myself on a sharp object which has left me with this scar on my forehead, so for me this is a serious issue which I feel is yet another critical obstacle to us who are visually impaired to participate in the electoral process in our country, meaning state-building is handicapped

\section{Lack of voter Education}

One participant from FODEP said;

It is very difficult for the visually impaired persons to participate to be included in the electoral process because this group of people has surely no adequate information with regards the electoral process. There is need to equip this group of people with information so that they are able to make well informed decisions and then we can be able to say that no one has been left behind. My thought is that, the government should have some laws and policies which incorporates the visually impaired in the electoral process.

Another participant from ZAPD said;

sensitization has not been well handled in Zambia regards the visually impaired and the electoral process because most of the times, issues to do with the elections information is either in normal font or on billboards or posters stuck all over the cities. This is a very big barricade for the visually impaired persons because as much as others are partially blind and others completely blind, both need a package, for example large font for the partially blind and braille materials for the completely blind, though this calls for the literate blind. Otherwise, the visually impaired need attention. This really hurts me in that I have blind relatives and they lack relevant information which should help them participant effectively in the electoral process.

In the same vain another ZFPD participant stated:

Information flow should be taken seriously because if not, information will not reach some groups of people in our country especially the visually impaired persons who are also human like any other human being, created by God. In this regard, am referring to information disseminated through rallies, this information is only suitable for the able bodied and not for the blind because of fear of the rampant electoral violence which is happening in our country today. People who are able bodied are losing their lives at these political rallies; What more a blind person? Hence, the reason why the government should come up with suitable policies for the visually impaired persons to access information without difficulties. Going forward,it is very important that, these rallies are made violence free so that any human being regardless of their physical status can access information from such rallies. Anyway the 
issue of the blind has to be addressed with some seriousness

\section{Lack of Electoral equipment}

One participant from FODEP said;

lack of equipment suitable for the blind people should really be considered. Though I know that there are some provisions for them at most polling stations but these people need quite a lot of equipment for them to effectively participate in the electoral process if their human rights have to be respected as our fellow human beings trending on an equal footing. As much as it may be expensive for the government, these people are not so many, so the government and other stakeholders can help procure some equipment suitable for their effective participation in the electoral process so that at least state building has a holistic approach. It's just my thought anyway, these people need some support because there is a lot of great potential untapped in this minority group

Another VI participant said;

We suffer alot in terms of walking because most of the equipment is not suitable for our use. I personally avoid the electoral gatherings because i fear for my life. So i would like to urge the government to provide good equipment for us to participate effectively in the electoral process

One participant from Electoral Commission of Zambia (ECZ) said;

The commission has made every possible move to ensure that there is the right equipment for the visually impaired so that the electoral process is inclusive but a lot still needs to be done

\section{E. How to make the electoral process inclusive}

There is need to intensify on the provision of the braille jacket-ballot paper which was piloted in the 2016 general elections by catering for the visually impaired illiterates through some sort of sound prompts because braille requires someone who can read and write. This is what one participant said;

The braille jacket which was used in the 2016 elections proved futile because I did not vote on my own but I was helped by someone because I could not operate it, so the braille jacket paper is not suitable for the visually impaired who have not been to school, so surely we need talking technology for us to feel we are voting in secrecy and solely our own choices not influenced by anyone because surely, I don't know for others but for me it's very uncomfortable. I was escorted up to the booth and $i$ was asked who I wanted to vote for but because it was a woman, $i$ respect women soi complied but still aggrieved because $i$ don't know what happened to my vote. Otherwise, i feel that the government means well but there is need for adequate sensitation and training regards the braille jacket use.

It was clear this serious matter. There is serious need to involve the visually impaired persons to participate in the electoral process at all levels as a way of enhancing inclusion of the visually impaired persons in the electoral process in Zambia.

\section{$F$. The right to be included in the electoral system}

According to the Zambia Agency of Persons with Disabilities, the Visually Impaired persons have the right to participate in the electoral process which might not be evidently seen by the public but their participation is low because of lack of sensitation in this regard. The views of the visually impaired regards their participation in the electoral process borders on self-discrimination and external discrimination, self rather internal discrimination in that the visually impaired feel they are blind and can never be recognized and external discrimination in that people feel the visually impaired don't see development ,hence no need for their participation. This is what one participant said;

it is imperative for the visually impaired persons to be included in the electoral process but of what benefit will it be to them if they cannot appreciate the current developmental projects going on? its probably because they can't see, so anyone who can't see what is being done cannot appreciate it no matter how nice it is, so it's not necessary to have them anywhere near the electoral process, we shall do it

\section{DISCUSSION OF THE FINDINGS}

In response to the study's research question one, the findings from the study showed that most respondents that were interviewed are aware that persons with disabilities have the right to vote or participate in the electoral process just like any person without a disability and that this is regardless of one's type of disability. This finding is in line with observations made Munemo (2015) who indicated that persons with disabilities should be seen as active citizens keen to be engaged in the political life of their communities. As well as voting in elections, persons with disabilities take part in other types of political activity in large numbers, including being members of political parties, attending political meetings and contacting elected officials. It is important to note that persons with disabilities have the same right to vote and stand for electoral office as candidates to be voted for during elections. Vickery (ed.) (2011) states that; while a death of data makes it difficult to assess the extent to which electoral complaints mechanisms are accessible to marginalized groups, access to justice generally is rife with barriers for persons with disabilities As from the findings, the respondents were asked about the barriers which exclude the visually impaired persons from the electoral process, a number of the respondents said 
that, lack of education is a challenge that has excluded the visually impaired persons from participating in the electoral process while other respondents said that, lack of suitable electoral equipment for the visually impaired has really hindered the participation of the visually impaired in the electoral process. Meanwhile, others also said that distance to the polling station and electoral violence respectively were an integral part of the many barriers they face. Therefore what stands out here is the fact that, there is lack of information or better still education tailored specifically for the visually impaired, which can enable them to participate adequately in the electoral process from grassroots to commission level. There has not been enough civic education with regards the electoral process and issues surrounding the process for the visually impaired persons. It was also observed that, political violence is yet another barrier to the participation of the visually impaired persons. This means pockets of violence during an election are a barrier to their participation. It is therefore, such conflicts which keep the visually impairedpersons away from the electoral process because they fear to be victimized or even being killed, hence creating a lapse or a gap in their participation. Although participation of people with disabilities in political processes is increasingly recognized as a human rights issue, little is known about how the key UNCRPD principles are translated into day-to-day practice, particularly in low and middle-income countries (World Health Organization and World Bank 2011 in Virendrakumar et al, 2018). The findings from the study have revealed that inaccessible infrastructure such as polling stations as one of the many challenges that persons with disabilities face in taking part in the electoral process. This challenge continues to act as a barrier and hinders persons with disabilities to be active citizens and be able to engage in the political life of their communities. This finding is in line with the observation made by Sackey (2015) who reported that People with disabilities who do manage to register to vote may find further barriers at the polling place. With votes being cast in a variety of public places, from school gyms to church basements to library meeting rooms, most of these voting facilities are inaccessible. This barrier excludes persons with disabilities from the opportunity to influence the development and implementation of $t$ laws and policies which shape their daily lives in their society.

Suffice to mention here that, the lack of voter education, lack of suitable equipment, distance to the polling station and rampant electoral violence (Magasu, 2016) obtaining in Zambia today are major barriers to the participation of the visually impaired persons in the electoral process. This means that there is need to address these issues so that the visually impaired people are included in the entire electoral process at their free will. The findings on the challenges that hinder participation of the visually impaired in the electoral process are in line to that by (Hurst ,2012), where he noted thatit's vital to empower disabled persons and to ensure their active participation in political, economic, social and cultural life in a way that is respectful and accommodating of their difference.

Meanwhile, the findings on the barriers that hinder the participation of the visually impaired persons in the electoral process were as follows: information in braille lack of tailored information, hence sensitization is not well carried out to the extent that there is language discrimination where the reporter would say a blind man, hence the fears of the visually impaired to participate in the electoral process. Selfdiscrimination and external discrimination, self being a situation where the visually impaired perceive the thoughts of the able bodied as being negative towards them and also the external discrimination where the able bodied would say the blind would never do anything because they can't see any development taking place, hence they can't participate in the electoral process, hence the political atmosphere is not good for the visually impaired to actively participate in the electoral process in Zambia.

Supplementary, the findings reveled other challenges that hinder the participation of the visually impaired in the electoral process as from not having enough materials in braille, financial constraints by the commission to fully engage the visually impaired in the electoral process, hence resources are a hindrance to developing a system which is whole embracing to all the citizenry so that the advocated for human rights are respected and adhered to. According to the findings, the other challenges which hinder the participation of the visually impaired persons in the electoral process were revealed whereas distance to the polling stations, resources to use in cases where they would want to aspire as candidates, assistance which depicts no secrecy in the voting process hence they feel used, while the uneducated visually impaired feel its unprofitable for them.

Meanwhile, it's imperative to state here that, the afore stated hindrances are very serious and in bleach of the human rights, hence it's very important that the Zambian government should bring on board different stakeholders who will help in sensitizing the visually impaired persons on their rights to voluntarily participate in the electoral process in order to bridge the gap which is prevailing currently where they feel sidelined in the process. The visually impaired persons feel that its unprofitable for them to vote in the 2021 elections, especially that there is no secrecy in the voting process for they were assisted in the 2016 elections amidst the braille jacket paper which was provided for them because most of them were not oriented on how to use it and some polling stations didn't have it. this statement though in contrast with the elections officer at the ECZ who said that; a braille paper jacket has was prepared for the 2016 elections of which, he said there was secrecy in this election, the statement is still contradictory in the sense that, the presiding officers who they said had taken oath were on the ground to assisting the visually impaired to slot in the ballot paper in the braille paper jacket and then help them identify a candidate of their choice 
still calls for assistance, hence no secrecy and a bleach of human rights as it stands.

The UDHR is a declaration adopted by the UN General Assembly in December, 1948. It is proclaimed as a common standard of achievement for all peoples and all nations in promoting respect for human rights and freedoms (paragraph 8 , preamble, universal declaration of human rights). It must be noted that although the UDHR was not intended to have any legal force. The principles proclaimed there in have crystallized into international customary law and thus binding. This was rightly stated by John to the effect that; the declaration is now considered to be an authoritative interpretation of the UN Charter, spelling out in considerable detail the meaning of the phrase "human rights and fundamental freedoms; which member's states agreed in the charter to promote and observe. The declaration as an authoritative listing of human rights has become a basic component of international customary law, binding all states, not only members of the United Nations (Mulenga, 2008).

The preamble begins by recognizing that the inherent dignity and the equal and inalienable rights of all members of the human family is the foundation of freedom, justice and peace in the world. The right to vote and the secret ballot are encapsulated under article 21 of the declaration. Article 21 (3) provides that;

The will of the people shall be the basis of the authority of government; this shall be expressed in periodic and genuine elections which shall be by universal and equal suffering and shall be held by secret vote or by equivalent free voting procedures.

It is important to note according to the above provisions, elections should be either by way of a secret ballot or equivalent free voting procedures. The equivalent voting procedures may include assistance. Thus in the absence of such, requests or consent, any measures that undermine the sanctity of the secret ballot violates Article 21 (3) above.

\section{Innovation}

This study proposes the implementation of the human rights model to the Electoral Commission of Zambia (a body that runs elections in Zambia). Essentially, this model aims at dismantling the discrimination faced by people because of their status. According to Degener (2017), the human rights model provides a theoretical framework for disability policy that emphasises the human dignity of (People with Disabilities) PWDs. Secondly, the human rights model incorporates both first and second generation human rights, in the sense that 'it encompasses both sets of human rights, civil and political as well as economic, social and cultural rights.'The human rights model respects the fact that some PWDs are indeed confronted by such challenging life situations and argues that such factors should be taken into account in the development of relevant social justice theories. The human rights model 'offers room for minority and cultural identification'. The human rights model recognises the fact that properly formulated prevention policy may be regarded as an instance of human rights protection for PWDs. The human rights model offers constructive proposals for improving the life situation of PWDs. When this model is adopted and implemented, it is expected that all the barriers Visually Impaired persons face in the electoral process will be stamped out.

\section{CONCLUSION}

In this study, an attempt has been made to establish the inclusion of the visually impaired persons in the electoral process in a human rights perspective with a view to giving possible strategies that could be adopted to address the issues contributing to their exclusion. The study, therefore, looks at current trends with a view to isolating the concerns and suggested improvements where possible in order to increase access and inclusion of the visually impaired persons in the electoral process in Zambia. However, the findings mainly bordered on the electoral needs of the VI in the electoral process; the level of inclusion of the visually impaired guaranteeing the participation of the visually impaired persons in national affairs to attain a comprehensive state building; the barricades that hinder the participation of the Visually Impaired in the electoral process; and the approaches or processes that can be put in place to ensure effective participation of the VI in the electoral process.

\section{RECOMMENDATIONS}

a. The electoral commission needs to put in place and implement approaches that will ensure that they reach out to voters with visual impairment with voter information packaged in formats suitable for the VIs such as braille materials, enlarged print and appropriate information technology.

b. Enforce Laws and policies that relate to the participation of the visually impaired in the electoral process to ensure that they are involved from grassroots to commission level so as to achieve comprehensive state building.

\section{REFERENCES}

[1] Article29 (a) (ii) of the convention on the rights of persons with Disabilities.

[2] Constitution of Zambia (1996), Lusaka, Government Printers

[3] Buck master and Thomas (2009).Social Inclusion and Social Citizenship; Towards A Truly Inclusive Society.www.researchgate.net

[4] Coser (2017).Association Membership and Generalized Trust: A Multilevel Model Across 31 Countries. The University of North Carolina press.

[5] Degener, T., (2017). 'A New Human Rights Model of Disability,' in V. Della Fina, R. Cera\& G. Palmisano (eds.), The United Nations convention on the rights of persons with disabilities: A commentary, pp. 41-60, Springer, Cham, Switzerland.

[6] European Union Agency for Fundamental Rights (2014). EU MIDIS main Results Report.en.m.wikipedia.org. 
[7] Hurst, A. (2012). Automatically Generated Tactile Visualizations of Coordinated Spaces. University

of Maryland/Baltimore county UMBC.

[8] ILO (2001). Inclusion of the People with Disabilities in Uganda.https://www.ilo.org/wem sp.

[9] International foundation for electoral system (2014), Annual report.www.ifes.org

[10] Magasu, O. (2016). An evaluation of the management of electoral conflicts in Zambia. A Case Study of Lusaka District Conflict Management Committees. Lusaka: UNZA. Palevel.unza.zm

[11] Meekosha, H, H. (1999).Political Activism and Identity Making: The Involvement of Women in Disability Rights Movement InAustralia.www.researchgate.net

[12] Mileji, P. (2016). The Electoral Process and the Visually Impaired in Zambia: Absolute or Discriminatory? Paleveel.unza.zm

[13] Mulenga, B. (2008).Human Rights in Zambia: Implementation of the convention against torture. Unza Press.

[14] Munemo, E, T. (2015). Enhancementof Access and Inclusion of People with Visual Impairments in the Electoral Process in Zimbambwe.PHD Thesis. Harare: Zimbabwe Open University
[15] Resource book on disability inclusion (2017). Lightof the World.www.light-for-the-world.org.

[16] Sackey, E. (2014).Disability and Political Participation in Ghana: AnAlternative perspective. Scandinavian journal of disability research 17(4):1-16

[17] Schur etal (2013), Peoplewith Disabilities: Sidelined or Mainstreamed. Cambridge press

[18] Sherwin,J..(2010). Leadership for Social Inclusion in The Lives of People with Disabilities. The international journal of leadership in public services. volume 6 supplement

[19] The National disability council on disability (2012) An independent federal agency committed to disability policy.ncd.gov

[20] The National Disability Council (2012), CRPD Jurisprudence. Disability Council International.Org

[21] Virendrakumar, B., Jolley, E., Badu, E. \& Schmidt, E. (2018). Disability inclusive elections in Africa: A systematic review of published and unpublished literature. Disability \& Society

[22] Vickery ed(2011 p.253), electoral compliance 